\title{
Inhibition of MEK/ERK/STAT3 signaling in oleuropein treatment inhibits myocardial ischemia/reperfusion
}

\author{
HONG-XU JIN $^{1 *}$, YUN-HU ZHANG ${ }^{2 *}$, RUO-NAN GUO ${ }^{3}$ and SU-NUAN ZHAO ${ }^{4}$ \\ Departments of ${ }^{1}$ Anesthesiology and ${ }^{2}$ General Medicine, Harrison International Peace Hospital, Hebei Medical University; \\ ${ }^{3}$ Department of Internal Medicine-Pediatrics, The Fifth People's Hospital, Hengshui, Hebei 053000; \\ ${ }^{4}$ Department of Pediatrics, Anping General Hospital, Anping, Hebei 053600, P.R. China
}

Received June 25, 2016; Accepted March 22, 2018

DOI: $10.3892 /$ ijmm.2018.3673

\begin{abstract}
Studies have shown that oleuropein has antifungal, anti-inflammatory, antiviral, antioxidant, anticancer and hypoglycemic functions. TTC solution staining was used to measure myocardial infarction size. A commercial kit was used to measure lactate dehydrogenase (LDH), creatinine kinase-MB (CK-MB), tumor necrosis factor- $\alpha$ (TNF- $\alpha)$, interleukin-1 $\beta$ (IL-1 $\beta$ ), IL 6, superoxide dismutase (SOD), glutathione (GSH), malondialdehyde (MDA) and catalase levels. Western blot analysis was used to measure p53, p-MEK p-ERK and $\mathrm{p}-\mathrm{I} \kappa \mathrm{B} \alpha$ protein expression. The present study reports that the protective effect of oleuropein also prevents against myocardial ischemia/reperfusion (myocardial I/R). The aim of this retrospective study was to evaluate this protective effect of oleuropein and the mechanisms by which myocardial $I / R$ is prevented. Oleuropein inhibited myocardial infarction size, CK-MB and LDH serum levels in a myocardial I/R rat model. Moreover, oleuropein also attenuated caspase-3 activity, and p53, phosphorylated (p)-mitogen-activated protein kinase kinase (MEK), p-extracellular signal-regulated protein kinase (ERK) and $\mathrm{p}-\mathrm{I} \kappa \mathrm{B} \alpha$ protein expression. TNF- $\alpha$, IL-1 $\beta$, IL-6 and MDA were decreased; SOD, GSH and catalase levels inhibited TNF- $\alpha$, IL-1 $\beta$, IL- 6 and MDA levels, and increased SOD, GSH and catalase levels in myocardial I/R rats treated with oleuropein. Rats orally administered the MEK inhibitor PD0325901, in addition to oleuropein, exhibited inhibited myocardial infarction size, CK-MB and LDH serum levels compared with rats treated with oleuropein only. Rats treated with MEK inhibitor also exhibited suppressed caspase-3
\end{abstract}

Correspondence to: Dr Hong-Xu Jin, Department of Anesthesiology, Harrison International Peace Hospital, Hebei Medical University, 180 Renmin East Road, Hengshui, Hebei 053000, P.R. China

E-mail: jijierenmao@126.com

*Contributed equally

Key words: mitogen-activated protein kinase kinase/extracellular signal-regulated protein kinase/signal transducer and activator of transcription 3, oleuropein, apoptotic, myocardial ischemia/reperfusion, inflammatory, oxidative stress activity, $\mathrm{p} 53$, p-MEK p-ERK and $\mathrm{p}-\mathrm{I} \kappa \mathrm{B} \alpha$ protein expression, TNF- $\alpha$, IL-1 $\beta$, IL-6, SOD, GSH, MDA and catalase levels, and induced p-signal transducer and activator of transcription 3 (STAT3) protein expression compared with rats treated with oleuropein only. Taken together, these results suggest that MEK/ERK/STAT3 signaling regulates the inhibition of myocardial $\mathrm{I} / \mathrm{R}$ in rats treated with oleuropein.

\section{Introduction}

With the continuous improvement of living standards and the accelerated pace of life, the morbidity and mortality rates of coronary atherosclerotic heart disease are increasing (1). The World Health Organization has indicated that coronary heart disease has become the leading cause of mortality in the world, and that acute myocardial infarction (AMI) is the leading cause of coronary heart disease-related mortality (2). With the continuous development of treatment, the morbidity rate of heart failure resulting from ventricular remodeling and of arrhythmia due to sympathetic remodeling is gradually increasing, while the acute-phase mortality rate of AMI is gradually decreasing $(3,4)$. Even though patients may receive optimized medical treatment, the overall mortality rate remains high.

Myocardial apoptosis is an autonomous process of programmed cell death in a series of gene regulation, of which the essence is physiological cell death (5). Myocardial apoptosis exists in the cardiovascular system, particularly during the physiological and pathological changes of AMI, and is an important cellular basis for a variety of cardiovascular diseases (6). The inhibition or reduction of myocardial apoptosis can reflect ventricular remodeling and cardiac function recovery following AMI, so the study of myocardial apoptosis is essential to evaluate the post-myocardial infarction heart function and associated drug efficacy (7).

AMI leads to an abnormal cellular environment due to an insufficient energy supply. The increase in cardiac compensatory contraction results in an elevated reactive oxygen species (ROS) level caused by membrane nicotinamide adenine dinucleotide phosphate (8). More seriously, the elevated ROS level triggers mitochondria to generate a large amount of oxidative stress (9). Oxidative stress can not only attack the cell membrane and organelles, but also cause the 
inflammatory response through mutual reinforcement with inflammatory cytokines, to further aggravate myocardial injury caused by myocardial infarction (10).

Heart inflammation can be summarized as a simple natural immune response and/or the combination of a natural immune response and an acquired immune response (11). The most typical characteristic of a natural immune response is the induction of inflammatory cytokine generation. In myocardial ischemia and heart failure, a natural immune response and an inflammatory response usually occur (12).

Oleuropein (Fig. 1) is a non-toxic split iridoid glycoside compound. Oleuropein increases the coronary blood flow of the rabbit isolated heart by $50 \%$, indicating antiarrhythmic and antispasmodic effects (13). Oleuropein obtained by the hydrolysis of olive leaf extract has antihypertensive effect (14). In addition, oleuropein is a strong angiotensin-converting enzyme inhibitor, for which the inhibitory effect is a result of the inherent 2,3-dihydroxy glutaraldehyde structures and their high reactivity (15). The corresponding aglycone produced by the enzymatic hydrolysis shows a similar effect to oleuropein, which has long-lasting hypotensive effect on rats, cats and dogs (16). Therefore, the present study aimed to investigate the protective effect and mechanisms of oleuropein in myocardial ischemia/reperfusion (I/R), and the possible role of extracellular signal-regulated protein kinase (ERK) signaling in the protective effects of oleuropein in myocardial I/R injury.

\section{Materials and methods}

Animals. All procedures were performed in accordance with the National Research Council's Guide of HARRISON International Peace Hospital, Hebei Medical University (Hengshu, Hebei, China) for Humane Care and Use of Laboratory Animals. All animal experiments were approved by the Medical Ethics Committee of HARRISON International Peace Hospital. Adult, male, Sprague-Dawley rats weighing 250-300 g were purchased from Hebei Medical University and maintained in controlled conditions of $22 \pm 2{ }^{\circ} \mathrm{C}$ and $60-70 \%$ humidity under a $12 \mathrm{~h}$ light-dark cycle (7:00 a.m. to 7:00 p.m.). Food and water were available ad libitum.

In vivo myocardial $I / R$ model and experimental groups. Firstly, a total of 26 rats (age, 5-6 weeks; weight, 200-250 g) were randomized into 3 groups: i) Control group $(n=6)$ : rats subjected to the surgical procedures without coronary occlusion; ii) myocardial I/R model group $(n=10)$ : 30 min of coronary occlusion followed by $3 \mathrm{~h}$ of reperfusion; and iii) Ole (20) group $(\mathrm{n}=10): 20 \mathrm{mg} / \mathrm{kg}$ of oleuropein for 2 consecutive days, then $30 \mathrm{~min}$ of coronary occlusion followed by $3 \mathrm{~h}$ of reperfusion.

Next, a total of 36 rats (age, 5-6 weeks; weight, 200-250 g) were randomized into 4 groups: i) Control group $(n=6)$ : rats subjected to the surgical procedures without coronary occlusion; ii) myocardial I/R model group $(n=10)$ : 30 min of coronary occlusion followed by $3 \mathrm{~h}$ of reperfusion; iii) Ole (20) group $(\mathrm{n}=10): 20 \mathrm{mg} / \mathrm{kg}$ of oleuropein for 2 consecutive days, then $30 \mathrm{~min}$ of coronary occlusion followed by $3 \mathrm{~h}$ of reperfusion; and iv) PD0325901 group: $3 \mathrm{mg} / \mathrm{kg}$ of PD0325901 and $20 \mathrm{mg} / \mathrm{kg}$ of oleuropein for 2 consecutive days, the $30 \mathrm{~min}$ of coronary occlusion followed by $3 \mathrm{~h}$ of reperfusion.

Rats were anesthetized by an intraperitoneal injection of $100 \mathrm{mg} / \mathrm{kg}$ ketamine (Sigma-Aldrich; Merck KGaA,

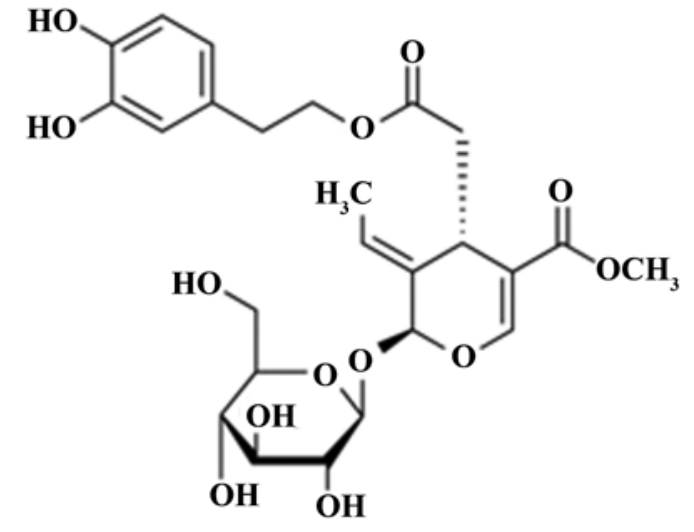

Figure 1. Constitutional formula of oleuropein.

Darmstadt, Germany). A left thoracotomy was performed to expose the hearts and the left anterior descending (LAD) artery was ligated at $2-3 \mathrm{~mm}$ at the pulmonary artery conus. Next, the left atrium was sutured using 6-0 silk Prolene. For reversible coronary occlusion, a small vinyl tube was placed on top of the vessel to form a snare. Regional ischemia was sustained in the heart for $30 \mathrm{~min}$ and reperfusion was then performed with release of the slipknot. Rats were sacrificed using decollation under anesthesia and the heart was peeled and frozen at $80^{\circ} \mathrm{C}$.

Measurement of myocardial infarction size. Following reperfusion for $3 \mathrm{~h}$, the LAD artery was removed and then $2 \%$ Evans blue (1.8-2 ml) was injected intravenously to denote the area at risk. The heart was peeled and frozen at $-80^{\circ} \mathrm{C}$ for $24 \mathrm{~h}$. The heart was then vertically cut into $1.5-\mathrm{mm}$ sections from the long axis to the area of ligation. Sections were incubated in $1 \%$ TTC solution for $30 \mathrm{~min}$ at $37^{\circ} \mathrm{C}$ and then incubated with $10 \%$ neutral buffered formalin overnight at room temperature.

Measurements of lactate dehydrogenase $(\mathrm{LDH})$, creatinine kinase-MB (CK-MB), tumor necrosis factor- $\alpha(T N F-\alpha)$, interleukin-1 $\beta$ (IL-1 $\beta)$, IL-6, superoxide dismutase (SOD), glutathione (GSH), malondialdehyde (MDA) and catalase levels. Subsequent to reperfusion, blood samples were collected from the right ventricle of every rat. These were centrifuged at $3,000 \mathrm{x} \mathrm{g}$ for $10 \mathrm{~min}$ at $4^{\circ} \mathrm{C}$ to separate the serum. $\mathrm{LDH}$ and CK-MB levels were evaluated using commercially available assay kits (Sigma-Aldrich; Merck KGaA). TNF- $\alpha$, IL-1 $\beta$, IL-6, SOD, GSH, MDA and catalase levels were evaluated using commercial enzyme-linked immunosorbent assay (ELISA) assay kits (Wuhan Boster Biological Technology, Inc., Wuhan, China).

Determination of apoptosis. Cytoplasmic proteins were prepared from heart tissues following reperfusion for $3 \mathrm{~h}$ and were lysed in ice-cold extraction buffer containing protease inhibitor cocktail (both Beyotime Institute of Technology, Shanghai, China) for $30 \mathrm{~min}$. Miscible liquids were centrifuged at $12,000 \mathrm{x} \mathrm{g}$ for $30 \mathrm{~min}$ and levels determined using a modified Bradford assay (Bio-Rad Laboratories, Inc., Hercules, CA, USA). Protein $(10 \mu \mathrm{g})$ was used to measure the activity levels of caspase- 3 using caspase-3 activity kit (Beyotime Institute of Technology). 


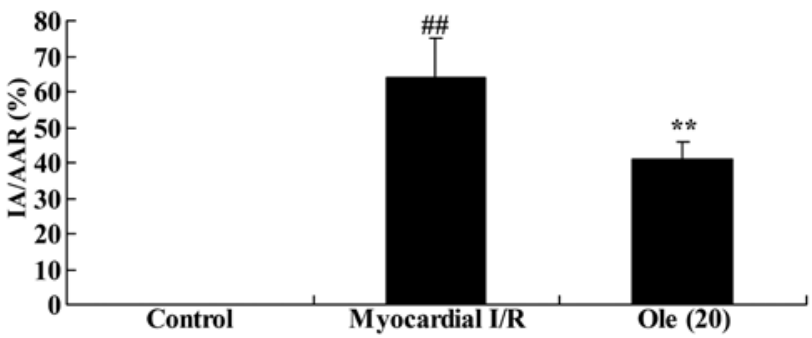

Figure 2. Protective effect of oleuropein against myocardial infarction size in myocardial I/R rats. Control, control group; myocardial I/R, myocardial $\mathrm{I} / \mathrm{R}$ model group; Ole (20), $20 \mathrm{mg} / \mathrm{kg} /$ day oleuropein treatment group. ${ }^{\# \#} \mathrm{P}<0.01$ vs. control group; ${ }^{* *} \mathrm{P}<0.01$ vs. myocardial I/R group. Ole, oleuropein; I/R, ischemia/reperfusion; IA, infarct area; AAR, area at risk.
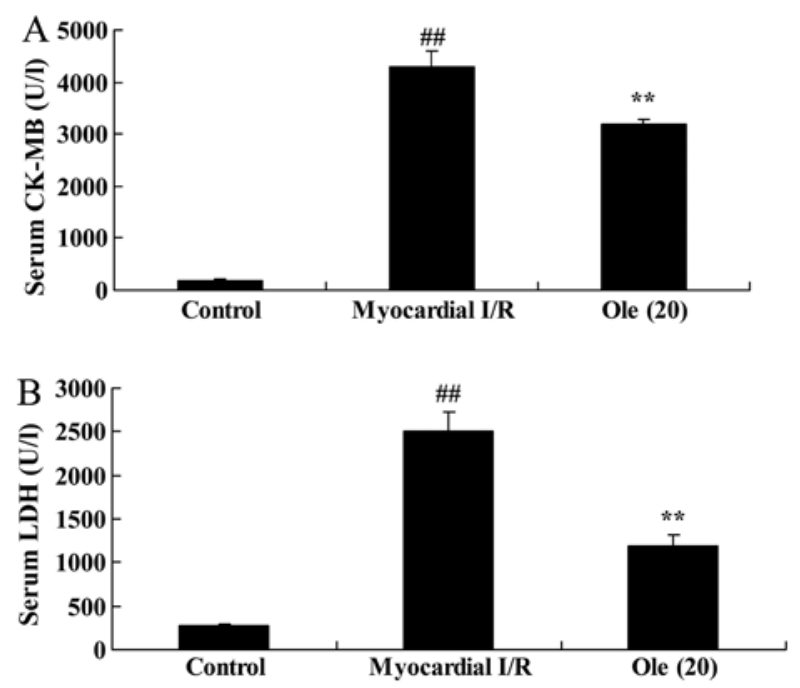

Figure 3. Protective effect of oleuropein against (A) CK-MB and (B) LDH serum levels in myocardial I/R rats. Control, control group; myocardial I/R, myocardial I/R model group; Ole (20), $20 \mathrm{mg} / \mathrm{kg} /$ day oleuropein treatment group. ${ }^{\# /} \mathrm{P}<0.01$ vs. control group; ${ }^{* *} \mathrm{P}<0.01$ vs. myocardial I/R group. Ole, oleuropein; $\mathrm{I} / \mathrm{R}$, ischemia/reperfusion; $\mathrm{CK}-\mathrm{MB}$, creatinine kinase-MB; $\mathrm{LDH}$, lactate dehydrogenase.

Western blot analysis. Cytoplasmic proteins were prepared from heart tissues following reperfusion for $3 \mathrm{~h}$ and were lysed in ice-cold extraction buffer containing protease inhibitor cocktail (both Beyotime Institute of Technology) for $30 \mathrm{~min}$. Miscible liquids were centrifuged at $12,000 \mathrm{x} \mathrm{g}$ for $30 \mathrm{~min}$ and levels determined using a modified Bradford assay (Bio-Rad Laboratories, Inc.). Protein (50-60 $\mu \mathrm{g}$ ) was separated by electrophoresis on $10 \%$ sodium dodecyl sulfate-polyacrylamide gels and transferred to nitrocellulose membranes (Bio-Rad Laboratories, Inc.). Membranes were washed with 5\% bovine serum albumin with Tris-buffered saline (TBS; $0.01 \mathrm{M}, \mathrm{pH} 7.4$ ) for $1 \mathrm{~h}$ at $37^{\circ} \mathrm{C}$ and incubated in a humidified chamber at $4^{\circ} \mathrm{C}$ overnight with primary antibodies against p53 (catalog no. 2527, 1:2,000 dilution), p-mitogen-activated protein kinase kinase (p-MEK; catalog no. 9127; 1:2,000 dilution), p-ERK (catalog no. 4370; 1:1,000 dilution), $\mathrm{p}-\mathrm{I} \kappa \mathrm{B} \alpha$ (catalog no. 2859, 1:1,000 dilution; all from Cell Signaling Technology, Inc., Danvers, MA, USA), p-signal transducer and activator of transcription 3 (p-STAT3; sc-8001-R; 1:1,000 dilution) and glyceraldehyde 3-phosphate dehydrogenase (GAPDH; 1:2,000; both from Santa Cruz Biotechnology, Inc., Santa Cruz, CA, USA). Membranes was washed with TBS with Tween 20 for $1 \mathrm{~h}$ at $37^{\circ} \mathrm{C}$ and then

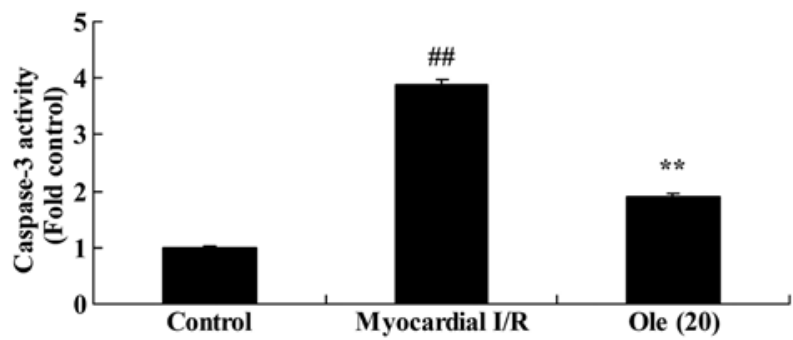

Figure 4. Protective effect of oleuropein against caspase-3 activity in myocardial I/R rats. Control, control group; myocardial I/R, myocardial $\mathrm{I} / \mathrm{R}$ model group; Ole (20), $20 \mathrm{mg} / \mathrm{kg} /$ day oleuropein treatment group. ${ }^{\# \#} \mathrm{P}<0.01$ vs. control group; ${ }^{* *} \mathrm{P}<0.01$ vs. myocardial I/R group. Ole, oleuropein; I/R, ischemia/reperfusion; IA, infarct area; AAR, area at risk.

incubated with peroxidase-conjugated secondary antibodies (sc-2004; 1:5,000 dilution, Santa Cruz Biotechnology, Inc.) for $1 \mathrm{~h}$ at $37^{\circ} \mathrm{C}$. The signals were detected with the enhanced chemiluminescence system (GE Healthcare, Chicago, IL, USA) and assayed by Image_Lab_3.0 (Bio-Rad Laboratories, Inc.).

Statistical analysis. Data are presented as the mean \pm standard error. Data were analyzed using StatSoft Statistica version 13.0 (StatSoft Inc., Tulsa, OK, USA). Statistical analyses were performed using one-way analysis of variance with repeated measures, followed by Bonferroni's post-hoc test. Statistical significance was defined as $\mathrm{P}<0.05$.

\section{Results}

Protective effect of oleuropein against myocardial infarction size in the myocardial I/R rats. Compared with rats in the normal control group, rats in the myocardial $\mathrm{I} / \mathrm{R}$ group exhibited a significant increase in myocardial infarction size (Fig. 2). Administration of oleuropein significantly inhibited the induction of myocardial infarction size by myocardial I/R injury compared with the myocardial I/R model (Fig. 2).

Protective effect of oleuropein against $C K-M B$ and $L D H$ serum levels in myocardial $\mathrm{I} / \mathrm{R}$ rats. CK-MB and LDH levels in the serum were also examined as indicators for myocardial injury evaluation in the present study. Compared with levels in the normal control group, there was a significant increase in CK-MB and LDH serum levels in the myocardial I/R rat group (Fig. 3). Consistently, rats with oleuropein treatment exhibited reduced levels of CK-MB and LDH compared with rats in the myocardial I/R group (Fig. 3).

Protective effect of oleuropein against caspase-3 activity expression in myocardial I/R rats. To research the protective effect of oleuropein against apoptosis, caspase-3 activity expression in the myocardial $I / R$ rat was researched. In comparison with that in the normal control group, a significant induction in caspase-3 activity was found in the myocardial I/R rat group (Fig. 4). However, rats with oleuropein administration exhibited significantly inhibited caspase-3 activity compared with rats in the myocardial I/R group (Fig. 4).

Protective effect of oleuropein against p53, MEK and ERK protein expression in myocardial $I / R$ rats. To further research 

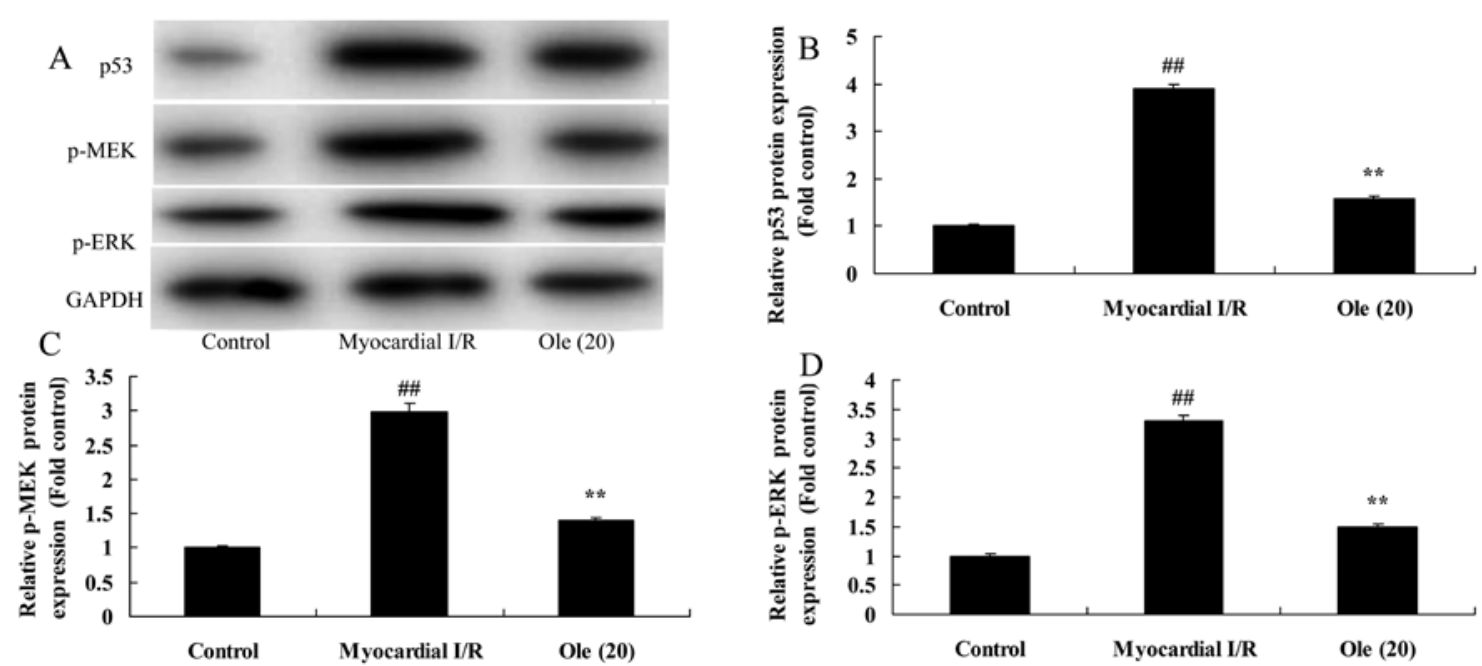

Figure 5. Protective effect of oleuropein against p53, MEK and ERK protein expression in myocardial I/R rats, as determined using (A) western blotting and statistical analysis of (B) p53, (C) p-MEK and (D) p-ERK protein expression. Control, control group; myocardial I/R, myocardial I/R model group; Ole (20), $20 \mathrm{mg} / \mathrm{kg} /$ day oleuropein treatment group. ${ }^{\# \#} \mathrm{P}<0.01$ vs. control group; ${ }^{* *} \mathrm{P}<0.01$ vs. myocardial I/R group. Ole, oleuropein; I/R, ischemia/reperfusion; ER, extracellular signal-regulated protein kinase; MEK, mitogen-activated protein kinase kinase; GAPDH, glyceraldehyde 3-phosphate dehydrogenase; p-, phosphorylated.
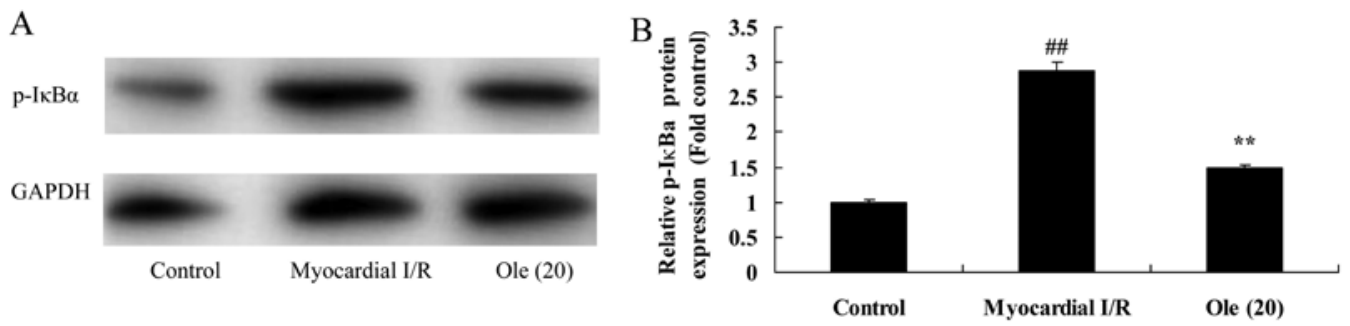

Figure 6. Protective effect of oleuropein against $\mathrm{p}-\mathrm{I} \kappa \mathrm{B} \alpha$ protein expression, as determined using (A) western blotting and (B) statistical analysis of $\mathrm{p}-\mathrm{I} \kappa \mathrm{B} \alpha$ protein expression in myocardial I/R rats. Control, control group; myocardial I/R, myocardial I/R model group; Ole (20), $20 \mathrm{mg} / \mathrm{kg} / \mathrm{day}$ oleuropein treatment group. ${ }^{\# \#} \mathrm{P}<0.01$ vs. control group; ${ }^{* *} \mathrm{P}<0.01$ vs. myocardial I/R group. Ole, oleuropein; I/R, ischemia/reperfusion; GAPDH, glyceraldehyde 3-phosphate dehydrogenase; p-, phosphorylated.
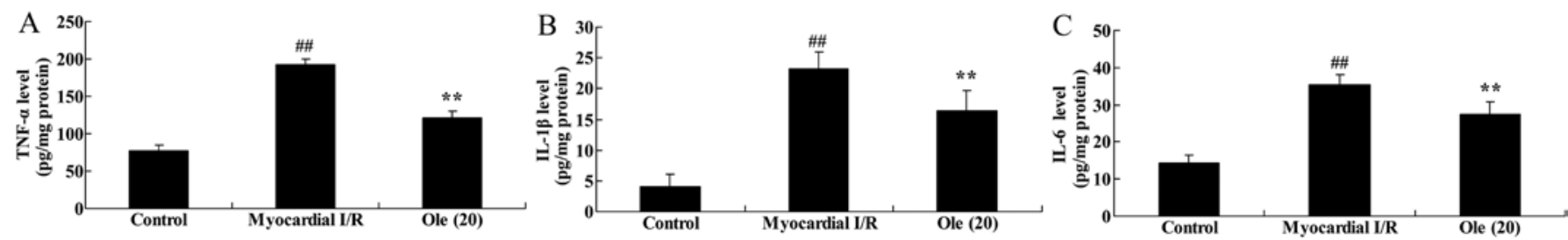

Figure 7. Protective effect of oleuropein against (A) TNF- $\alpha$, (B) IL-1 $\beta$ and (C) IL-6 levels in myocardial I/R rats. Control, control group; myocardial I/R, myocardial I/R model group; Ole (20), $20 \mathrm{mg} / \mathrm{kg} /$ day oleuropein treatment group. ${ }^{\# \#} \mathrm{P}<0.01 \mathrm{vs}$. control group; ${ }^{* *} \mathrm{P}<0.01$ vs. myocardial I/R group. Ole, oleuropein; $\mathrm{I} / \mathrm{R}$, ischemia/reperfusion; IL, interleukin; TNF- $\alpha$, tumor necrosis factor- $\alpha$.

the mechanism behind the protective effect of oleuropein against apoptosis, p53, MEK and ERK protein expression in myocardial $\mathrm{I} / \mathrm{R}$ rats was measured using western blot analysis. The induction of p53, p-MEK and p-ERK protein expression was markedly observed in the myocardial $\mathrm{I} / \mathrm{R}$ model group in comparison with that in the normal control group (Fig. 5). The oleuropein treatment group showed significantly suppressed induction of p53, p-MEK and p-ERK protein expression compared with the myocardial I/R group.

Protective effect of oleuropein against $p-I \kappa B \alpha$ protein expression in myocardial $I / R$ rats. To investigate the mechanism behind the protective effect of oleuropein against inflammation factors, $\mathrm{p}-\mathrm{I} \kappa \mathrm{B} \alpha$ protein expression in myocardial $\mathrm{I} / \mathrm{R}$ rats was measured using western blot analysis. Myocardial $\mathrm{I} / \mathrm{R}$ significantly induced the $\mathrm{p}-\mathrm{I} \kappa \mathrm{B} \alpha$ protein expression in the myocardial I/R rat group compared with that in the normal control group (Fig. 6). The oleuropein-treated group showed significant suppression of $\mathrm{p}$-IкB $\alpha$ protein expression compared with the myocardial I/R rat group (Fig. 6).

Protective effect of oleuropein against TNF- $\alpha, I L-1 \beta$ and IL-6 levels in myocardial $I / R$ rats. To investigate the anti-inflammatory effect of oleuropein against myocardial I/R, TNF- $\alpha$, IL-1 $\beta$ and IL- 6 levels were measured using ELISA assay kits. The results demonstrated that the TNF- $\alpha$, IL- $1 \beta$ and IL-6 levels were significantly induced in the myocardial I/R model 

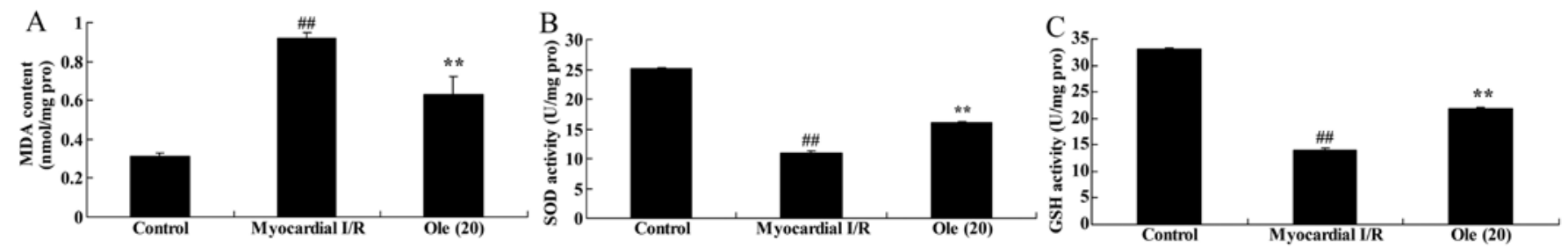

Figure 8. Protective effect of oleuropein against (A) SOD, (B) GSH and (C) MDA levels in myocardial I/R rats. Control, control group; myocardial I/R, myocardial I/R model group; Ole (20), $20 \mathrm{mg} / \mathrm{kg} /$ day oleuropein treatment group. ${ }^{\# \#} \mathrm{P}<0.01$ vs. control group; ${ }^{* *} \mathrm{P}<0.01$ vs. myocardial $\mathrm{I} / \mathrm{R}$ group. Ole, oleuropein; $\mathrm{I} / \mathrm{R}$, ischemia/reperfusion; SOD, superoxide dismutase; GSH, glutathione; MDA, malondialdehyde; pro, protein.
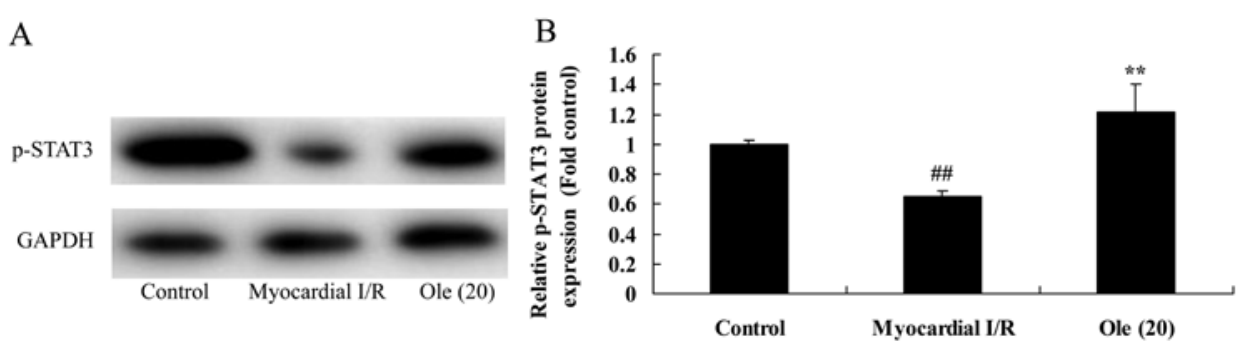

Figure 9. Protective effect of oleuropein against p-STAT3 protein expression, as determined using (A) western blotting and (B) statistical analysis of p-STAT protein expression in myocardial I/R rats. Control, control group; myocardial I/R, myocardial I/R model group; Ole (20), $20 \mathrm{mg} / \mathrm{kg} / \mathrm{day}$ oleuropein treatment group. ${ }^{\# \#} \mathrm{P}<0.01$ vs. control group; ${ }^{* *} \mathrm{P}<0.01$ vs. myocardial I/R group. Ole, oleuropein; $\mathrm{I} / \mathrm{R}$, ischemia/reperfusion; $\mathrm{p}$-, phosphorylated; STAT3, signal transducer and activator of transcription 3; GAPDH, glyceraldehyde 3-phosphate dehydrogenase.

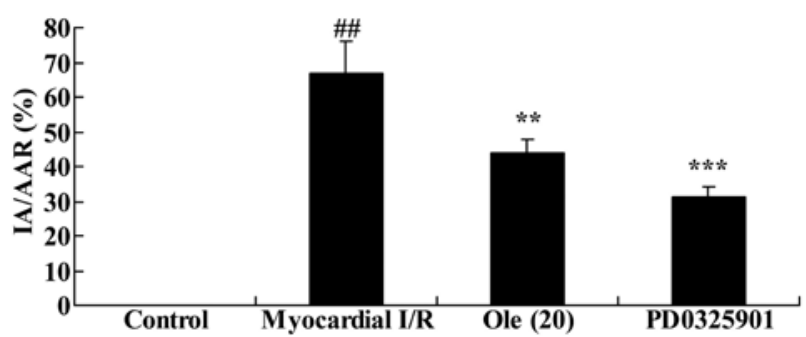

Figure 10. Inhibition of mitogen-activated protein kinase kinase increases the protective effect of oleuropein against myocardial infarction size in myocardial $\mathrm{I} / \mathrm{R}$ rats. Control, control group; myocardial I/R, myocardial I/R model group; Ole (20), $20 \mathrm{mg} / \mathrm{kg} / \mathrm{day}$ oleuropein treatment group; PD0325901, $3 \mathrm{mg} / \mathrm{kg}$ PD0325901 + $20 \mathrm{mg} / \mathrm{kg} /$ day oleuropein treatment group. ${ }^{\#} \mathrm{P}<0.01 \mathrm{vs}$. contro group; ${ }^{* *} \mathrm{P}<0.01$ vs. myocardial I/R group; ${ }^{* * *} \mathrm{P}<0.01$ vs. Ole (20) group. Ole, oleuropein; I/R, ischemia/reperfusion; IA, infarct area; AAR, area at risk.

group compared with that in the normal control group (Fig. 7). The oleuropein-treated group exhibited significantly reduced induction of TNF- $\alpha$, IL- $1 \beta$ and IL- 6 levels by myocardial I/R compared with the myocardial I/R group (Fig. 7).

Protective effect of oleuropein against SOD, GSH, MDA levels in myocardial $I / R$ rats. Furthermore, the protective effect of oleuropein against oxidative stress in myocardial I/R rats was probed by detecting SOD, GSH, MDA levels using ELISA assay kits. The inhibition of SOD and GSH, and the increase in MDA levels was significantly different in the myocardial I/R rat compared with that in the normal control group (Fig. 8). The oleuropein-treated rats exhibited significantly increased levels of SOD and GSH, and a significantly decreased MDA level compared with rats in the myocardial I/R model group (Fig. 8).

Protective effect of oleuropein on p-STAT3 protein expression in myocardial I/R rats. Additionally, the protective effect of oleuropein against p-STAT3 (p-STAT3) protein expression

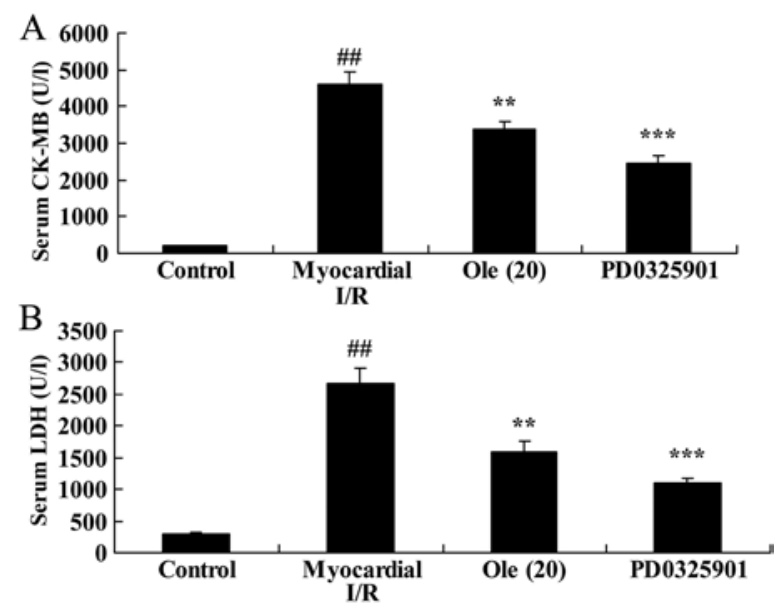

Figure 11. Inhibition of mitogen-activated protein kinase kinase increases the protective effect of oleuropein against (A) CK-MB and (B) LDH serum levels in myocardial I/R rats. Control, control group; myocardial I/R, myocardial I/R model group; Ole (20), $20 \mathrm{mg} / \mathrm{kg} /$ day oleuropein treatment group; PD0325901, $3 \mathrm{mg} / \mathrm{kg}$ PD0325901 + $20 \mathrm{mg} / \mathrm{kg} /$ day oleuropein treatment group. ${ }^{\# \#} \mathrm{P}<0.01$ vs. control group; ${ }^{* *} \mathrm{P}<0.01$ vs. myocardial I/R group; ${ }^{* * *} \mathrm{P}<0.01$ vs. Ole (20) group. Ole, oleuropein; I/R, ischemia/reperfusion; LDH lactate dehydrogenase; CK-MB, creatinine kiase-MB.

was investigated in the myocardial I/R rat. As shown in Fig. 9, the suppression of p-STAT3 protein expression was markedly increased in the myocardial $\mathrm{I} / \mathrm{R}$ rat group compared with that in the normal control group. Rats treated with oleuropein exhibited significantly induced p-STAT3 protein expression compared with rats in the myocardial I/R group (Fig. 9).

Inhibition of MEK increases the protective effect of oleuropein against myocardial infarction size in myocardial $I / R$ rats. To provide evidence linking MEK to the effect of oleuropein, PD0325901, a MEK inhibitor, was introduced to the myocardial $\mathrm{I} / \mathrm{R}$ rats to analyze how the inhibition of MEK affected 


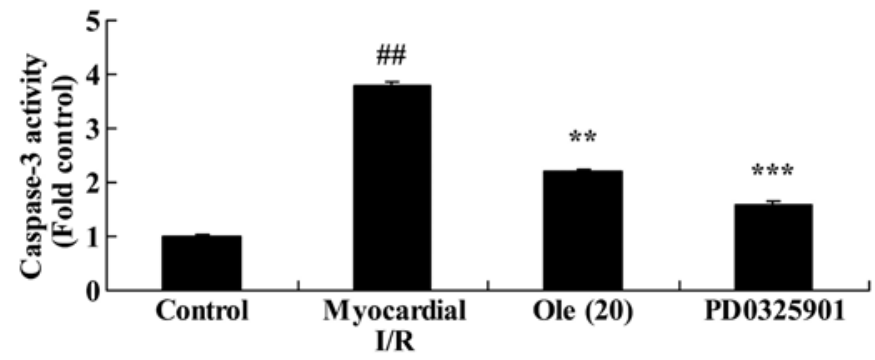

Figure 12. Inhibition of mitogen-activated protein kinase kinase increases the protective effect of oleuropein against caspase-3 activity in myocardial I/R rats. Control, control group; myocardial I/R, myocardial I/R model group; Ole (20), $20 \mathrm{mg} / \mathrm{kg} / \mathrm{day}$ oleuropein treatment group; PD0325901, $3 \mathrm{mg} / \mathrm{kg}$ $\mathrm{PD} 0325901+20 \mathrm{mg} / \mathrm{kg} /$ day oleuropein treatment group. ${ }^{\#} \mathrm{P}<0.01 \mathrm{vs}$. control group; ${ }^{* *} \mathrm{P}<0.01$ vs. myocardial I/R group; ${ }^{* * *} \mathrm{P}<0.01$ vs. Ole (20) group. Ole, oleuropein; I/R, ischemia/reperfusion; MEK, mitogen-activated protein kinase kinase.

the protective effect of oleuropein against myocardial infarction size. The group treated with PD0325901 and oleuropein exhibited a significantly inhibited myocardial infarction size compared with the group treated with oleuropein only (Fig. 10).

Inhibition of $M E K$ increases the protective effect of oleuropein against $C K-M B$ and $L D H$ serum levels in myocardial $I / R$ rats. To investigate the mechanism of oleuropein against myocardial I/R, CK-MB and LDH serum levels were examined in myocardial $\mathrm{I} / \mathrm{R}$ rats treated with oleuropein following inhibition of MEK. Rats with MEK inhibition exhibited significantly decreased CK-MB and LDH serum levels compared rats treated with oleuropein only (Fig. 11).

Inhibition of MEK increases the protective effect of oleuropein against caspase-3 activity expression in myocardial $I / R$ rats. To determine whether the inhibition of MEK affects apoptosis in oleuropein-treated myocardial I/R rats, caspase- 3 activity expression was examined after the addition of PD0325901. Rats with MEK inhibition showed significantly decreased caspase-3 activity compared with rats treated with oleuropein only (Fig. 12).

Inhibition of MEK increases the protective effect of oleuropein against p53, MEK and ERK protein expression in myocardial $I / R$ rats. To further determine whether the inhibition of MEK regulates p53, MEK and ERK protein expression in myocardial I/R rats treated with oleuropein, protein levels were analyzed. Following MEK inhibition, the protein expression of p53, p-MEK and p-ERK was significantly suppressed compared with that in the group treated with oleuropein only (Fig. 13A-D).

Inhibition of MEK increases the protective effect of oleuropein against $p-I \kappa B \alpha$ protein expression in myocardial $I / R$ rats. To determine whether the inhibition of MEK increased the anti-inflammatory effect of oleuropein in myocardial I/R rats, $\mathrm{p}-\mathrm{I} \kappa \mathrm{B} \alpha$ protein expression was detected using western blot analysis. Following MEK inhibition, the protein expression of $\mathrm{p}-\mathrm{I} \kappa \mathrm{B} \alpha$ was also significantly suppressed compared with that in the group treated with oleuropein only (Fig. 13A and E).

Inhibition of MEK increases the protective effect of oleuropein against TNF- $\alpha, I L-1 \beta$ and IL-6 levels in myocardial $I / R$ rats.
To further determine whether the inhibition of MEK affects the anti-inflammatory effect of oleuropein in myocardial I/R rats, TNF- $\alpha$, IL-1 $\beta$ and IL-6 levels were analyzed. It was found that the inhibition of MEK significantly inhibited TNF- $\alpha$, IL-1 $\beta$ and IL-6 levels in the rats treated with PD0325901 and oleuropein compared with that in rats treated with oleuropein only (Fig. 14).

Inhibition of MEK increases the protective effect of oleuropein against SOD, GSH and MDA levels in myocardial I/R rats. Next, the effect of the inhibition of MEK on the anti-oxidative action of oleuropein was examined in the myocardial I/R rats. With the inhibition of MEK, a significant increase in SOD and GSH levels, and a significant decrease in MDA level was found in the PD0325901 group compared with that in the group treated with oleuropein only (Fig. 15).

Inhibition of MEK increases the protective effect of oleuropein on $p$-STAT3 in myocardial I/R rats. Lastly, whether the inhibition of MEK increased the protective effect of oleuropein against $\mathrm{p}$-STAT3 was examined. The protein expression of p-STAT3 was significantly promoted in the PD0325901 group compared with that in the group treated with oleuropein only (Fig. 16).

\section{Discussion}

Myocardial ischemia refers to the reduction of heart blood perfusion, resulting in cardiac oxygen reduction and abnormal myocardial energy metabolism, which is a pathological state that cannot support heart function (1). Coronary plaques or occlusion and instability of coronary atherosclerosis caused by coronary artery stenosis are major causes of myocardial ischemia (17). Patients with recurrent myocardial ischemia may suffer from angina, myocardial stunning, myocardial hibernation, ischemic preconditioning, acute coronary syndrome, AMI or even cardiac rupture (18). In the present study, oleuropein significantly inhibited the myocardial infarction size and reduced the levels of CK-MB and LDH in the myocardial I/R rat. Nekooeian et al (15) reported that oleuropein offered cardioprotection via its antioxidant properties.

ERK1/2 is a subfamily of the mitogen-activated protein kinase (MAPK) signaling pathway, which exists widely in various stages of the cell cycle and serves an important role in gene transcription and cell cycle processes (19). At present, ERK1/2 is regarded to promote both cell survival and proliferation, and apoptosis, for which the mechanism depends on the sub-localization of ERK1/2 in cells and the activated signaling molecules downstream (19). According to the traditional view, ERK1/2 enters into the nucleus to activate cell survival and proliferation; however, if the phosphorylated ERK1/2 stays in the cytoplasm for the long term, it may interact with a series of pro-apoptotic proteins to initiate the apoptosis of cells (20). The present study found that oleuropein significantly suppressed the induction of p53, p-MEK and p-ERK protein expression in myocardial I/R rats. Potočnjak et al (21) suggest that oleuropein attenuated cisplatin-induced acute renal injury through inhibition of p53 and ERK signaling in mice.

Cardiac cells are a class of mature cells with terminal differentiation and without the proliferation ability (22). 
A
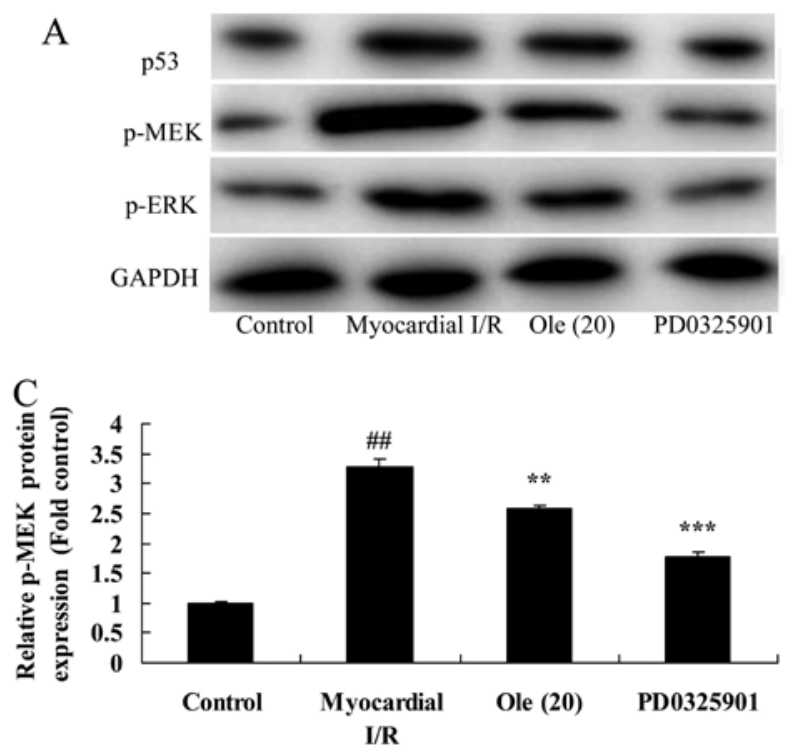

$\mathrm{E}$

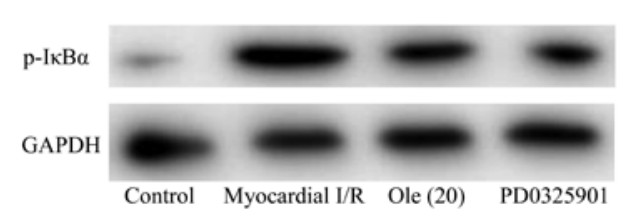

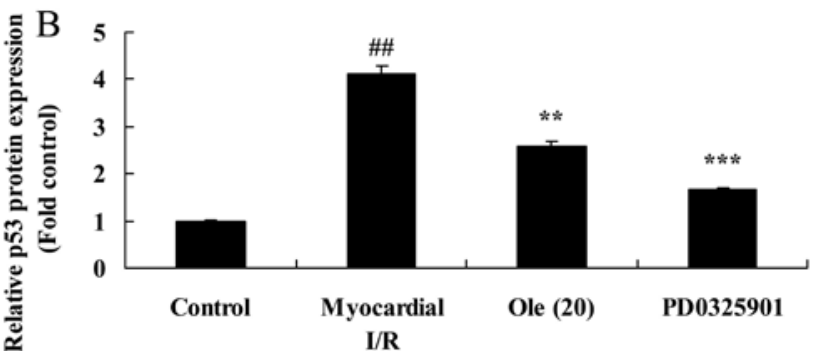
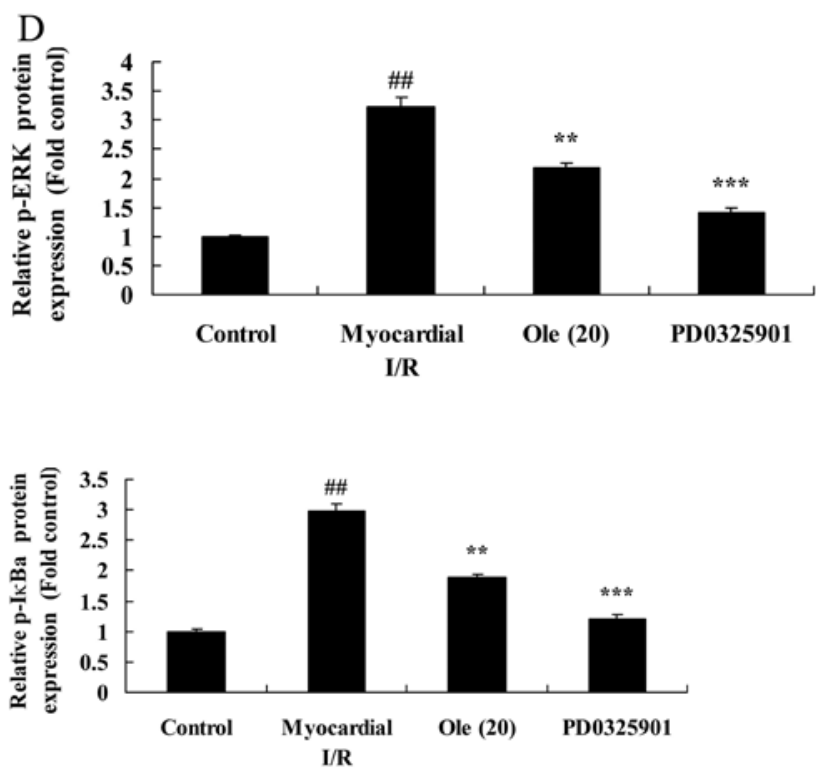

Figure 13. Inhibition of MEK increases the protective effect of oleuropein against p53, MEK, ERK and p-IкB $\alpha$ protein expression, as determined using western blotting (A) and statistical analysis of (B) p53, (C) p-MEK, (D) p-ERK and (E) p-IкB $\alpha$ protein expression in myocardial I/R rats. Control, control group; myocardial I/R, myocardial I/R model group; Ole (20), $20 \mathrm{mg} / \mathrm{kg} / \mathrm{day}$ of oleuropein treated group; PD0325901,3 mg $/ \mathrm{kg}$ of PD0325901 + $20 \mathrm{mg} / \mathrm{kg} / \mathrm{day}$ of oleuropein treated group. ${ }^{\# \#} \mathrm{p}<0.01$ vs. the control group; ${ }^{* *} \mathrm{p}<0.01$ vs. the myocardial I/R group; ${ }^{* * * *} \mathrm{p}<0.01$ vs. Ole (20) group. Ole, oleuropein; I/R, ischemia/reperfusion; p-, phosphorylated; MEK, mitogen-activated protein kinase kinase; ERK, extracellular signal-regulated protein kinase; GAPDH, glyceraldehyde 3-phosphate dehydrogenase.
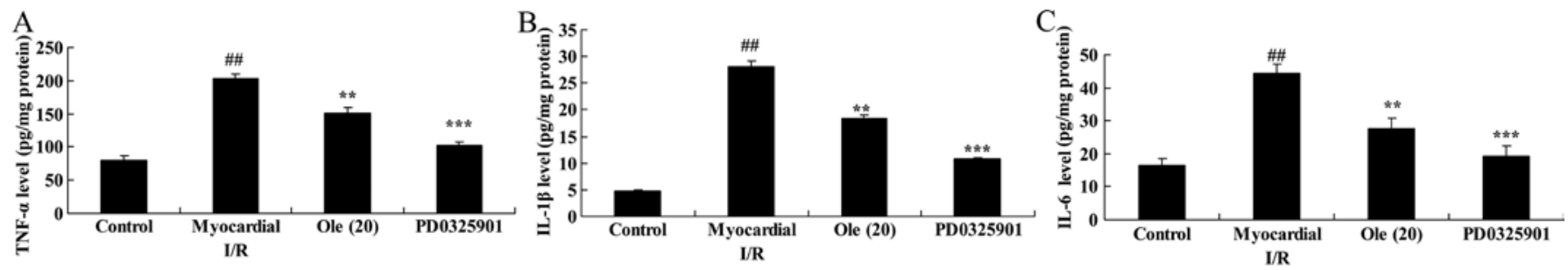

Figure 14. Inhibition of mitogen-activated protein kinase kinase increases the protective effect of oleuropein against (A) TNF- $\alpha$, (B) IL-1 $\beta$ and (C) IL-6 levels in myocardial I/R rats. Control, control group; myocardial I/R, myocardial I/R model group; Ole (20), $20 \mathrm{mg} / \mathrm{kg} /$ day oleuropein treatment group; PD0325901, $3 \mathrm{mg} / \mathrm{kg}$ PD0325901 $+20 \mathrm{mg} / \mathrm{kg} /$ day oleuropein treatment group. ${ }^{\# \#} \mathrm{P}<0.01$ vs. control group; ${ }^{* * *} \mathrm{P}<0.01$ vs. myocardial I/R group; ${ }^{* * * *} \mathrm{P}<0.01 \mathrm{vs}$. Ole (20) group. Ole, oleuropein; I/R, ischemia/reperfusion; IL, interleukin; TNF- $\alpha$, tumor necrosis factor- $\alpha$.
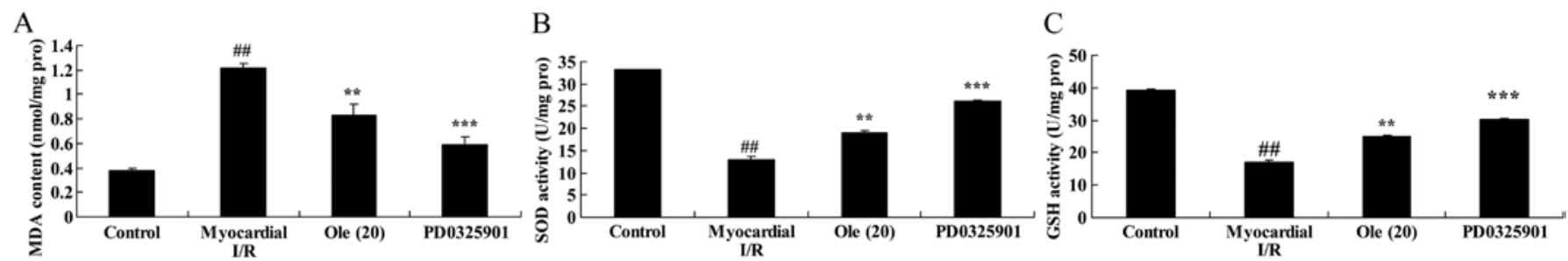

Figure 15. Inhibition of mitogen-activated protein kinase kinase increases the protective effect of oleuropein against (A) SOD, (B) GSH and (C) MDA levels in myocardial I/R rats. Control, control group; myocardial I/R, myocardial I/R model group; Ole (20), $20 \mathrm{mg} / \mathrm{kg} / \mathrm{day}$ oleuropein treatment group; PD0325901, $3 \mathrm{mg} / \mathrm{kg}$ PD0325901 $+20 \mathrm{mg} / \mathrm{kg} /$ day oleuropein treatment group. ${ }^{* \#} \mathrm{P}<0.01$ vs. control group; ${ }^{* * *} \mathrm{P}<0.01$ vs. myocardial I/R group; ${ }^{* * * *} \mathrm{P}<0.01 \mathrm{vs}$. Ole $(20)$ group. Ole, oleuropein; I/R, ischemia/reperfusion; SOD, superoxide dismutase; GSH, glutathione; MDA, malondialdehyde; pro, protein. 
A

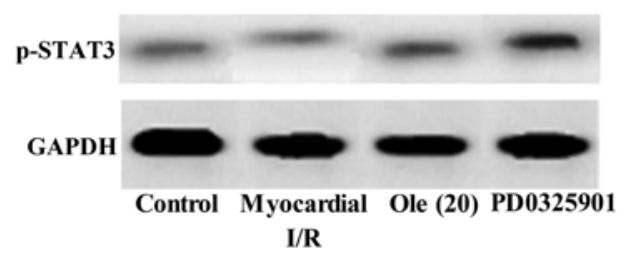

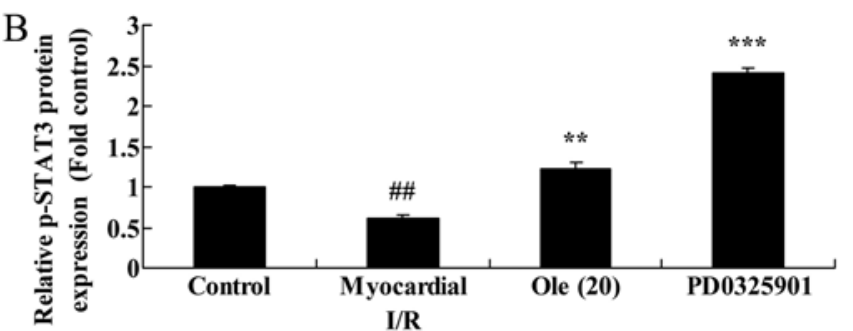

Figure 16. Inhibition of mitogen-activated protein kinase kinase increases the protective effect of oleuropein against p-STAT3 protein expression, as determined using (A) western blotting and (B) statistical analysis of p-STAT3 protein expression in myocardial I/R rats. Control, control group; myocardial I/R, myocardial I/R model group; Ole (20), $20 \mathrm{mg} / \mathrm{kg} /$ day oleuropein treatment group; PD0325901, $3 \mathrm{mg} / \mathrm{kg}$ PD0325901 + 20 mg/kg/day oleuropein treatment group. ${ }^{\# \#} \mathrm{P}<0.01$ vs. control group; ${ }^{* *} \mathrm{P}<0.01$ vs. myocardial I/R group; ${ }^{* * *} \mathrm{P}<0.01$ vs. Ole (20) group. Ole, oleuropein; I/R, ischemia/reperfusion; p-, phosphorylated; STAT3, signal transducer and activator of transcription 3; GAPDH, glyceraldehyde 3-phosphate dehydrogenase.

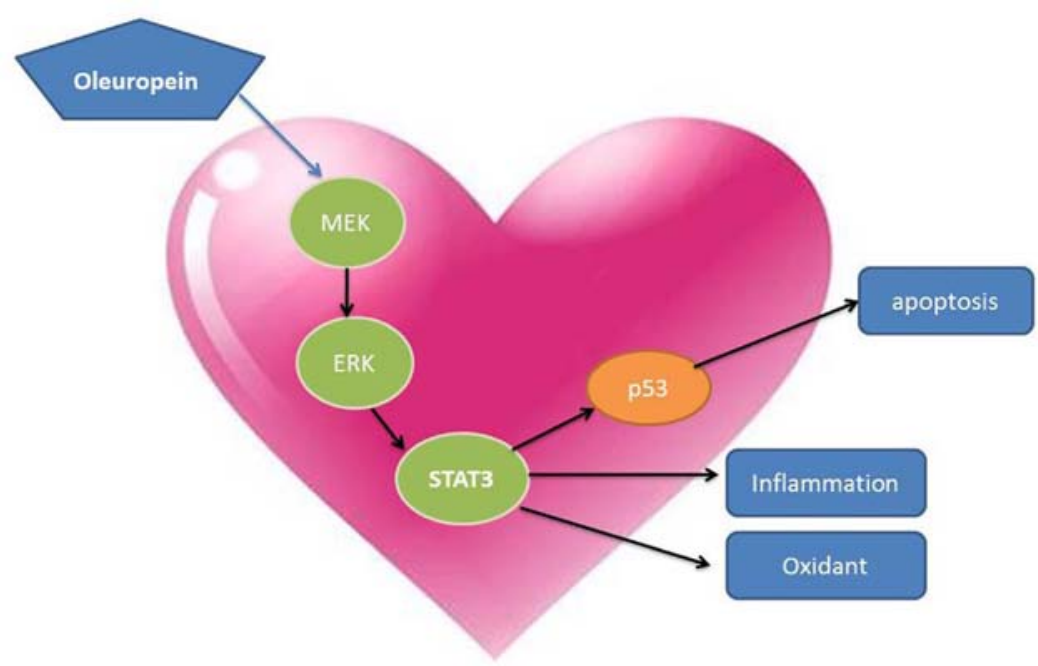

Figure 17. MEK/extracellular signal-regulated protein kinase/STAT3 signaling regulates the inhibition of myocardial ischemia/reperfusion treated by oleuropein. MEK, mitogen-activated protein kinase kinase; STAT3, signal transducer and activator of transcription 3.

Myocardial cell apoptosis is a type of programmed cell death that is performed in a series of gene regulation by activating cell 'suicide' program through certain signaling pathways under certain physiological and pathological conditions (22). It has been indicated that the apoptosis in myocardial cells serves an important role in the physiological and pathological developmental processes and maintenance of normal heart morphology, and is considered to be the 'cellular basis' for the change from compensatory changes to pathological changes (23). Meanwhile, the present study found that oleuropein administration significantly inhibited caspase-3 activity in the myocardial I/R rat. Impellizzeri et al (13) showed that oleuropein may be useful in the treatment of various inflammatory diseases via suppression of caspase- 3 in mice with spinal cord injury.

In AMI, long-term hypoxia and ischemia of myocardial cells leads to aerobic metabolic disorder due to coronary occlusion, and then causes hyperemia and edema of myocardial interstitial cells, and myocardial cell degeneration and necrosis, accompanied by a large amount of inflammatory cell infiltration (10). A large number of free radicals are generated in the tissues and the peroxide destruction of oxygen free radicals mainly damages the structure and function of myocardial cell membranes, damages the mitochondria, cuts off the cells energy supply and destroys lysosomes to cause cell autolysis (24). The myocardium of accelerated ischemia develops from reversible damage to irreversible degeneration and necrosis. Malignant arrhythmia appears, thereby causing ventricular remodeling and cardiac dysfunction (24). Recanalization and reperfusion therapy is the most effective treatment now, but I/R can further damage the myocardium, for which the important mechanism is oxidative stress; the greater the duration of myocardial ischemia and hypoxia the greater the oxidative stress and myocardial damage, and the more severe the disease (25). The present study showed that oleuropein significantly increased the inhibition of SOD and $\mathrm{GSH}$, and inhibited the activation of MDA level in myocardial I/R rats. Nekooeian et al (15) indicated that oleuropein offered cardioprotection through its antioxidant properties in rats with simultaneous type 2 diabetes.

AMI is the myocardial necrosis caused by acute and persistent myocardial ischemia and hypoxia. Following AMI, changes such as myocardial ischemia, hypoxia and increases in wall tension among, other others, may induce the formation of the inflammatory response (26). In the inflammatory process subsequent to AMI, IL- 6 and TNF- $\alpha$ serve greater roles. IL-6 promotes the increased expression of intercellular adhesion molecule-1 by myocardial cells via the regulation of 
the synthesis of liver C-reactive protein (CRP) and a series of biochemical processes of the liver in the acute phase reaction, thereby enhancing the adhesion of neutrophils and the release of oxygen free radicals (27). TNF- $\alpha$ directly damages endothelial cells to induce the CRP synthesis pathway to produce an effect by enhancing leukocyte chemotaxis (27). The aforementioned inflammatory processes will inevitably result in myocardial cell injury or myocardial fibrosis. Thus far, studies have shown that inflammation serves an important role in the development of myocardial fibrosis (28). In the present study, it was found that oleuropein significantly reduced the induction of TNF- $\alpha$, IL-1 $\beta$ and IL-6 levels by myocardial I/R. Giner et al (16) also showed oleuropein to be a protective agent against colitis-associated colorectal cancer via reduction of intestinal IL-6, IFN- $\gamma$, TNF- $\alpha$ and IL-17A concentration in c57bl/6 mice.

In the resting condition of cells, nuclear factor- $\kappa \mathrm{B}(\mathrm{NF}-\kappa \mathrm{B})$ is bound to $\mathrm{I} \kappa \mathrm{B}$ to form a complex present in the cytoplasm. When subjected to external stimuli, including cytokines, oxidants, protein kinase $\mathrm{C}$ activator, viruses, ultraviolet and lipopolysaccharides, $\mathrm{I} \kappa \mathrm{Bs}$ are degraded, thus releasing the free $N F-\kappa B$ dimers. At this time, the $N F-\kappa B$ is transported from the cytoplasm to the nucleus, which influences the transcription of various adhesion cytokines, immune receptors, acute-phase proteins and stress-response protein genes (29). Studies have shown that NF- $\kappa \mathrm{B}$ is a central regulator for stress and the inflammatory response, and that it not only serves a role in immune regulation, but that its signaling pathway has also been extensively involved in cell survival, differentiation, proliferation and apoptosis, playing an important role in the occurrence, development and outcome of numerous diseases $(30,31)$. The present study showed that $\mathrm{p}-\mathrm{I} \kappa \mathrm{B} \alpha$ protein expression was significantly suppressed in myocardial I/R rats with oleuropein treatment compared with that in rats without treatment. Campolo et al (32) demonstrated that oleuropein inhibits secondary events of intestinal ischemia/reperfusion injury through $\mathrm{NF}-\kappa \mathrm{B}$ and $\mathrm{I} \kappa \mathrm{B} \alpha$.

ERK is the most important and classical route that is best studied for the MAPK path, the path is the nodes and common pathway of multiple pro-proliferation signal transduction pathways (33). Previous results have shown that angiotensin II (AngII) may lead to pathological myocardial hypertrophy and myocardial fibrosis by AngII type I receptor $\left(\mathrm{AT}_{1} \mathrm{R}\right)$-mediated protein kinase $\mathrm{C}$ (PKC)-ERK1/ERK2 pathway signaling (34). The binding of AngII and $\mathrm{AT}_{1} \mathrm{R}$ can activate a number of signaling molecules downstream, including phospholipase $\mathrm{C}$, phospholipase D and PKC. PKC activates ERK1/2, thus achieving the signal transduction within the cell and the activation of nuclear gene transcription (35). Notably, in the present study, inhibition of MEK expression could inhibit myocardial infarction size and CK-MB and LDH serum levels, suppress caspase-3 activity and p53, p-MEK p-ERK and p-I $\kappa \mathrm{B} \alpha$ protein expression, and inhibit TNF- $\alpha$, IL-1 $\beta$, IL- 6 and MDA levels and increase SOD, GSH and catalase levels in myocardial I/R rats treated with oleuropein.

In conclusion, the results of the current study showed that oleuropein inhibited myocardial infarction size, and CK-MB and LDH serum levels in myocardial I/R rats through anti-inflammation, anti-oxidant, anti-apoptosis and inhibition of MEK/ERK/STAT3 signaling. Moreover, inhibition of the MEK/ERK/STAT3 signaling pathway may serve a key role in the protective effects of oleuropein against myocardial I/R in rats (Fig. 17).

\section{Acknowledgements}

Not applocable.

\section{Funding}

No funding was received.

\section{Availability of data and materials}

The analyzed data sets generated during the study are available from the corresponding author on reasonable request.

\section{Authors' contributions}

HXJ designed the experiment. YHZ, RNG and SNZ performed the experiment. HXJ analyzed the data and wrote the manuscript. All authors read and approved the final manuscript.

\section{Ethics approval and consent to participate}

All animal experiments were approved by the Medical Ethics Committee of Harrisson International Peace Hospital.

\section{Consent for publication}

Not applicable.

\section{Competing interests}

The authors declare that they have no competing interests.

\section{References}

1. Nicholls SJ, Cavender MA, Kastelein JJ, Schwartz G, Waters DD, Rosenson RS, Bash D and Hislop C: Inhibition of secretory phospholipase $\mathrm{A}(2)$ in patients with acute coronary syndromes: Rationale and design of the vascular inflammation suppression to treat acute coronary syndrome for 16 weeks (VISTA-16) trial. Cardiovasc Drugs Ther 26: 71-75, 2012.

2. Holme I, Szarek M, Cater NB, Faergeman O, Kastelein JJ, Olsson AG, Tikkanen MJ, Larsen ML, Lindahl C and Pedersen TR; Incremental Decrease in End Points Through Aggressive Lipid Lowering Study Group: Adherence-adjusted efficacy with intensive versus standard statin therapy in patients with acute myocardial infarction in the IDEAL study. Eur $J$ Cardiovasc Prev Rehabil 16: 315-320, 2009.

3. Vemulapalli S, Zhou Y, Gutberlet M, Kumar AS, Mills JS, Blaxill J, Smalling R, Ohman EM and Patel MR: Importance of total ischemic time and preprocedural infarct-related artery blood flow in predicting infarct size in patients with anterior wall myocardial infarction (from the CRISP-AMI Trial). Am J Cardiol 112: 911-917, 2013.

4. Winter JL, Lindefjeld DS, Veas N, Guarda E, Valdebenito M, Méndez M, Pérez O, Zuanic K, Mestas M and Martínez A: Angiographic and electrocardiographic parameters of myocardial reperfusion in angioplasty of patients with ST elevation acute myocardial infarction loaded with ticagrelor or clopidogrel (MICAMI-TICLO trial). Cardiovasc Revasc Med 15: 284-288, 2014.

5. Wei C, Wang Y, Li M, Li H, Lu X, Shao H and Xu C: Spermine inhibits endoplasmic reticulum stress-induced apoptosis: A new strategy to prevent cardiomyocyte apoptosis. Cell Physiol Biochem 38: 531-544, 2016. 
6. Zhang H, Wang Z, Feng SJ, Xu L, Shi HX, Chen LL, Yuan GD, Yan W, Zhuang W, Zhang YQ, et al: PEDF improves cardiac function in rats with acute myocardial infarction via inhibiting vascular permeability and cardiomyocyte apoptosis. Int J Mol Sci 16: 5618-5634, 2015.

7. Ale A, Siebenhaar F, Kosanke K, Aichler M, Radrich K, Heydrich S, Schiemann M, Bielicki I, Noel PB, Braren R, et al: Cardioprotective $\mathrm{C}-\mathrm{kit}^{+}$bone marrow cells attenuate apoptosis after acute myocardial infarction in mice - in-vivo assessment with fluorescence molecular imaging. Theranostics 3: 903-913, 2013.

8. Li L, Guo Y, Zhai H, Yin Y, Zhang J, Chen H, Wang L, Li N, Liu R and Xia Y: Aging increases the susceptivity of MSCs to reactive oxygen species and impairs their therapeutic potency for myocardial infarction. PLoS One 9: e111850, 2014.

9. Becatti M, Fiorillo C, Gori AM, Marcucci R, Paniccia R, Giusti B, Violi F, Pignatelli P, Gensini GF and Abbate R: Platelet and leukocyte ROS production and lipoperoxidation are associated with high platelet reactivity in Non-ST elevation myocardial infarction (NSTEMI) patients on dual antiplatelet treatment. Atherosclerosis 231: 392-400, 2013

10. Correa F, Martínez-Abundis E, Hernández-Reséndiz S, García N Buelna-Chontal M, Arreguín F and Zazueta C: Pharmacological strategies to contend against myocardial reperfusion damage: Diverse chemicals for multiple targets. Curr Med Chem 17: 2261-2273, 2010.

11. Sun SJ, Wu XP, Song HL and Li GQ: Baicalin ameliorates isoproterenol-induced acute myocardial infarction through iNOS, inflammation, oxidative stress and P38MAPK pathway in rat. Int J Clin Exp Med 8: 22063-22072, 2015.

12. Protti A, Dong X, Andia ME, Yu B, Dokukina K, Chaubey S, Phinikaridou A, Vizcay-Barrena G, Taupitz M, Botnar RM, et al: Assessment of inflammation with a very small iron-oxide particle in a murine model of reperfused myocardial infarction. J Magn Reson Imaging 39: 598-608, 2014.

13. Impellizzeri D, Esposito E, Mazzon E, Paterniti I, Di Paola R, Bramanti P, Morittu VM, Procopio A, Perri E, Britti D, et al: The effects of a polyphenol present in olive oil, oleuropein aglycone, in an experimental model of spinal cord injury in mice. Biochem Pharmacol 83: 1413-1426, 2012.

14. Lapi D, Di Maro M, Mastantuono T, Battiloro L, Sabatino L, Muscariello E and Colantuoni A: Effects of oleuropein and pinoresinol on microvascular damage induced by hypoperfusion and reperfusion in rat pial circulation. Microcirculation 22: 79-90, 2015

15. Nekooeian AA, Khalili A and Khosravi MB: Oleuropein offers cardioprotection in rats with simultaneous type 2 diabetes and renal hypertension. Indian J Pharmacol 46: 398-403, 2014.

16. Giner E, Recio MC, Ríos JL, Cerdá-Nicolás JM and Giner RM: Chemopreventive effect of oleuropein in colitis-associated colorectal cancer in c57bl/6 mice. Mol Nutr Food Res 60 242-255, 2016.

17. Elbarouni B, Cantor WJ, Ducas J, Borgundvaag B, Džavík V Heffernan M, Buller CE, Langer A, Goodman SG and Yan AT; TRANSFER-AMI Trial Investigators: Efficacy of an early invasive strategy after fibrinolysis in ST-elevation myocardial infarction relative to the extent of coronary artery disease. Can J Cardiol 30: 1555-1561, 2014.

18. Boghdady A and Elbadry MI: Comparison of successful myocardial reperfusion and adverse events in patients with ST-elevation myocardial infarction who underwent rescue percutaneous coronary intervention after failed fibrinolytic therapy with versus without manual coronary thrombus aspiration. Am J Cardiol 116: 1185-1192, 2015.

19. She T, Wang X, Gan Y, Kuang D, Yue J, Ni J, Zhao X and Wang G: Hyperglycemia suppresses cardiac stem cell homing to peri-infarcted myocardium via regulation of ERK1/2 and p38 MAPK activities. Int J Mol Med 30: 1313-1320, 2012.

20. Przybyt E, Krenning G, Brinker MG and Harmsen MC: Adipose stromal cells primed with hypoxia and inflammation enhance cardiomyocyte proliferation rate in vitro through STAT3 and Erk1/2. J Transl Med 11: 39, 2013.
21. Potočnjak I, Škoda M, Pernjak-Pugel E, Peršić MP and Domitrović R: Oral administration of oleuropein attenuates cisplatin-induced acute renal injury in mice through inhibition of ERK signaling. Mol Nutr Food Res 60: 530-541, 2016.

22. Yang X, Qin Y, Shao S, Yu Y, Zhang C, Dong H, Lv G and Dong S: MicroRNA-214 Inhibits Left Ventricular Remodeling in an Acute Myocardial Infarction Rat Model by Suppressing Cellular Apoptosis via the Phosphatase and Tensin Homolog (PTEN). Int Heart J 57: 247-250, 2016.

23. Zhang RL, Guo Z, Wang LL and Wu J: Degeneration of capsaicin sensitive sensory nerves enhances myocardial injury in acute myocardial infarction in rats. Int J Cardiol 160: 41-47, 2012.

24. Sygitowicz G, Maciejak A, Piniewska-Juraszek J, Pawlak M, Góra M, Burzyńska B, Dłużniewski M, Opolski $G$ and Sitkiewicz D: Interindividual variability of atorvastatin treatment influence on the MPO gene expression in patients after acute myocardial infarction. Acta Biochim Pol 63: 1014, 2016.

25. Mladenka P, Filipský T, Ríha M, Vávrová J, Holecková M, Palicka V and Hrdina R: The relationship of oxidative stress markers and parameters of myocardial function in a rat model of cardiotoxicity. Free Radic Biol Med 75 (Suppl 1): S42, 2014.

26. Carvalheiro T, Velada I, Valado A, Mendes F, Martinho A, António N, Gonçalves L, Providência L, Pais ML and Paiva A: Phenotypic and functional alterations on inflammatory peripheral blood cells after acute myocardial infarction. J Cardiovasc Transl Res 5: 309-320, 2012.

27. Shrivastava AK, Singh HV, Raizada A and Singh SK: Serial measurement of lipid profile and inflammatory markers in patients with acute myocardial infarction. EXCLI J 14: 517-526, 2015.

28. Prato FS, Butler J, Sykes J, Keenliside L, Blackwood KJ, Thompson RT, White JA, Mikami Y, Thiessen JD and Wisenberg G: Can the inflammatory response be evaluated using 18F-FDG within zones of microvascular obstruction after myocardial infarction? J Nucl Med 56: 299-304, 2015.

29. Xia KP, Ca HM and Shao CZ: Protective effect of notoginsenoside R1 in a rat model of myocardial ischemia reperfusion injury by regulation of vitamin $\mathrm{D} 3$ upregulated protein $1 / \mathrm{NF}-\kappa \mathrm{B}$ pathway. Pharmazie 70: 740-744, 2015.

30. Xu H, Wang D, Peng C, Huang X, Ou M, Wang N, Wang P, Zhou L and Ye X: Rabbit sera containing compound danshen dripping pill attenuate leukocytes adhesion to TNF-alpha-activated human umbilical vein endothelial cells by suppressing endothelial ICAM-1 and VCAM-1 expression through NF-kappaB signaling pathway. J Cardiovasc Pharmacol 63: 323-332, 2014

31. Arslan S, Korkmaz Ö, Özbilüm N and Berkan Ö: Association between NF- $\kappa \mathrm{BI}$ and NF- $\kappa \mathrm{BIA}$ polymorphisms and coronary artery disease. Biomed Rep 3: 736-740, 2015.

32. Campolo M, Di Paola R, Impellizzeri D, Crupi R, Morittu VM, Procopio A, Perri E, Britti D, Peli A, Esposito E, et al: Effects of a polyphenol present in olive oil, oleuropein aglycone, in a murine model of intestinal ischemia/reperfusion injury. J Leukoc Biol 93: 277-287, 2013.

33. Grossi V, Lucarelli G, Forte G, Peserico A, Matrone A, Germani A, Rutigliano M, Stella A, Bagnulo R, Loconte D, et al: Loss of STK11 expression is an early event in prostate carcinogenesis and predicts therapeutic response to targeted therapy against MAPK/p38. Autophagy 11: 2102-2113, 2015.

34. Armstrong SC: Protein kinase activation and myocardial ischemia/reperfusion injury. Cardiovasc Res 61: 427-436, 2004.

35. Ruisong M, Xiaorong $\mathrm{H}$, Gangying $\mathrm{H}$, Chunfeng $\mathrm{Y}$, Changjiang Z, Xuefei L, Yuanhong L and Hong J: The protective role of interleukin-33 in myocardial ischemia and reperfusion is associated with decreased HMGB1 expression and upregulation of the p38 MAPK signaling pathway. PLoS One 10: e0143064, 2015. 